\title{
MONITORING KUALITAS AIR DI WADUK Ir. H. DJUANDA
}

\author{
Siti Mariyam*) \\ *Teknisi Litkayasa pada Loka Riset Pemacuan Stok Ikan, Jatiluhur
}

Teregristasi I tgl. 15/9/2005; Disetujui terbit tgl. 26/1/2007

\section{PENDAHULUAN}

Waduk Ir. H. Djuanda merupakan suatu badan air yang berasal dari bendungan Sungai Citarum, selesai dibangun tahun 1967. Waduk ini terletak di Kabupaten Purwakarta Jawa Barat, dikelilingi oleh pegunungan kapur yang agak gundul, memiliki luas permukaan sekitar $8.300 \mathrm{Ha}$ dan ketinggian $111 \mathrm{~m}$ dpl (Sarnita 1981). Waduk Ir. H. Djuanda tahun 2004 memiliki kedalaman maksimum sekitar 35-58 m. Aktifitas yang dilakukan dalam waduk ini (Gambar 1) adalah pembangkit listrik, irigasi, perikanan, wisata, transportasi, sumber air minum, dan lain-lain. Kegiatan tersebut memerlukan kualitas air yang layak.

Jumlah KJA di Waduk Ir. H. Djuanda di tahun 2004 sebesar 4.700 unit, jumlah ini sudah melebihi batas yang dianjurkan. Sehubungan dengan kegiatan budi daya ikan yang intensif maka perlu di lakukan monitoring kualitas air dengan tujuan untuk memberikan informasi tentang kualitas air di dalam waduk tersebut. Monitoring kualitas air dilaksanakan oleh Loka Riset Pemacuan Stok Ikan Jatiluhur secara periodik setiap bulan, yang dilakukan pada 11 stasiun pengamatan dari inlet (Parung kalong) sampai DAM (Gambar 2). Untuk mendapatkan data yang akurat dalam waktu yang singkat maka perlu dipersiapkan lebih dahulu metode, alat, dan pereaksi yang dibutuhkan.

\section{METODE}

\section{Metode Penelitian}

Monitoring kualitas air ini dilakukan dengan metode survei lapangan dan analisa laboratorium. Pengambilan contoh air dengan metode stratified (Niellsen \& Johnson, 1985) pada 5 kedalaman (permukaan $2 \mathrm{~m}, 4 \mathrm{~m}, 8 \mathrm{~m}$, dan dasar perairan) Pengambilan contoh air dilakukan pada tanggal 20 setiap bulan. Stasiun pengambilan contoh di (I) Parung Kalong, (II) Sodong, (III) Bojong, (IV) Jamaras, (V) Kerenceng, (VI) Karamba, (VII) Cilalawi, (VIII) PDAM, (IX) Taroko, (X) Baras Barat, dan (XI) DAM.

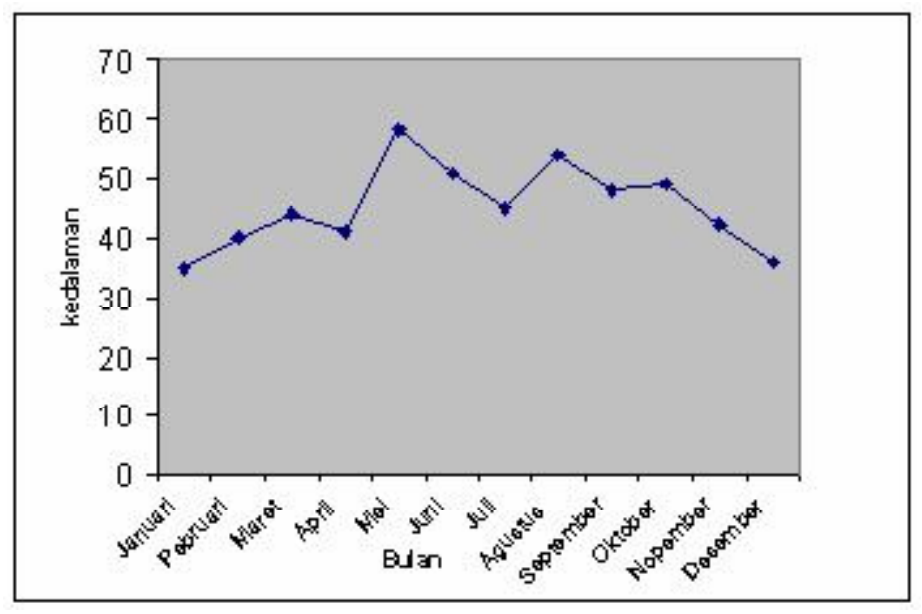

Gambar 1. Kedalaman air maksimum di Waduk Ir. H. Djuanda bulan Januari sampai Desember. 


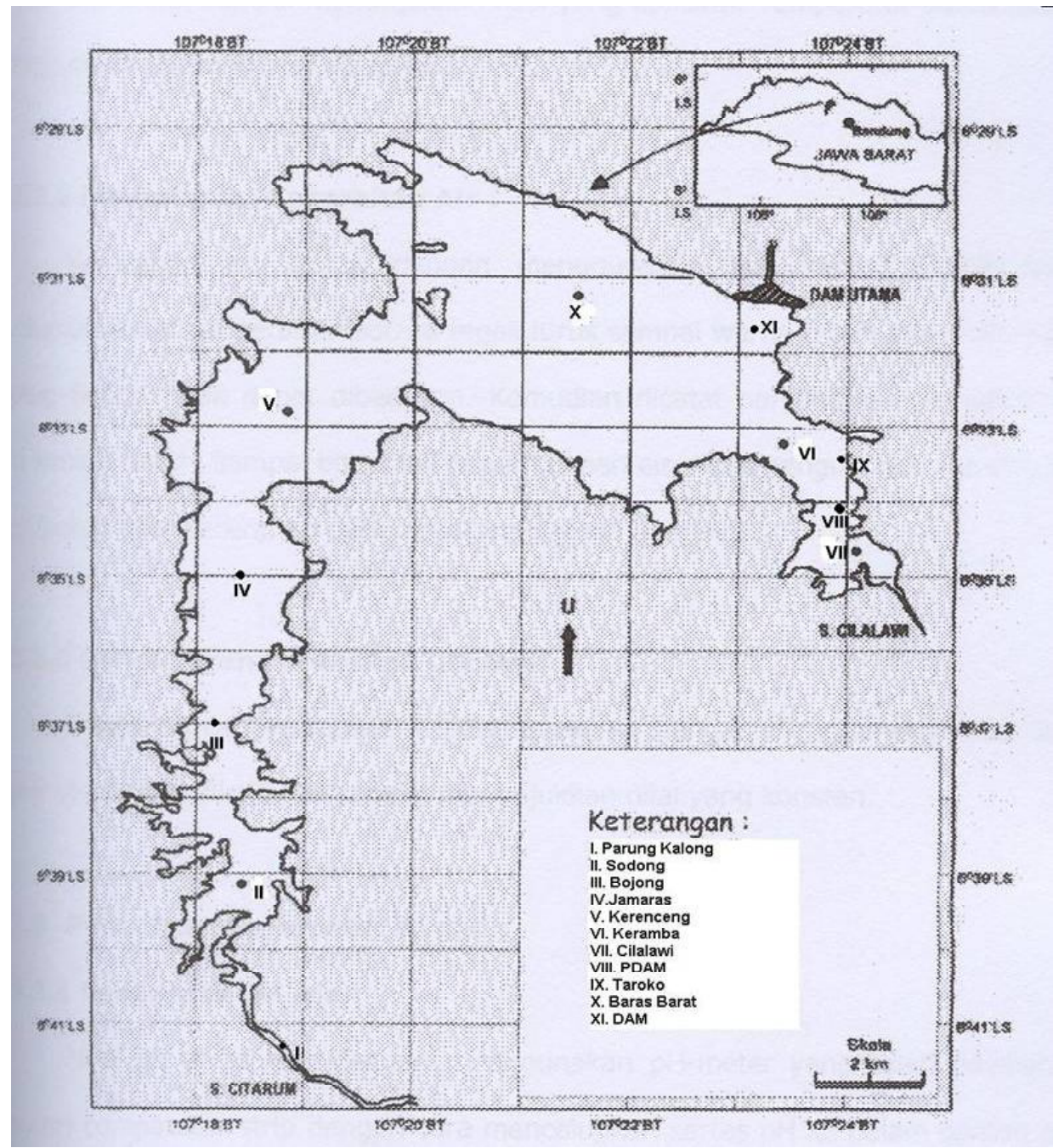

Gambar 2. Peta stasiun pengamatan monitoring kualitas air.

\section{Alat di Lapangan}

1. DO meter merek YSI 55 untuk mengukur oksigen terlarut.

2. Conduktivi meter merek YSI 30 untuk mengukur daya hantar listrik dan temperatur.

3. LX-102 light meter merek Lutron untuk mengukur intensitas cahaya.

4. Thermometer air raksa untuk mengukur suhu udara dan suhu air.

5. Piring secchi untuk mengukur kecerahan air.

6. $\mathrm{pH}$ indikator untuk mengukur asam basa air.

7. Kemmerer Water Sample untuk mengambil contoh air dari setiap kedalaman yang sudah ditentukan yaitu $0 \mathrm{~m}, 2 \mathrm{~m}, 4 \mathrm{~m}, 8 \mathrm{~m}$, dan dasar perairan.

8. Alat titrasi untuk mengukur total alkalinitas dan karbon dioksida.

\section{Alat di Laboratorium}

1. Kertas saring Whatman ukuran $42 \mathrm{~mm}$ untuk menyaring contoh air dari lapangan.

2. Corong dari plastik sebagai alat bantu meletakkan kertas saring.

3. Erlenmeyer, wadah untuk menampung contoh air yang sudah disaring.

4. Gelas ukur alat untuk mengambil contoh air.

5. Tabung reaksi, wadah untuk menampung contoh air yang akan ditambah pereaksi.

6. Pipet tetes $10 \mathrm{ml}$, alat untuk menambah pereaksi ke dalam contoh air.

7. Cuvet, wadah untuk menampung contoh air yang akan dibaca konsentrasinya.

8. Themo Spectronic merek GENESYS 20, alat untuk membaca konsentrasi setiap parameter. 


\section{Bahan di Lapangan}

1. pHindikator.

2. Phenolphtalin indikator $\mathrm{CO}_{2}$ sebanyak 2 tetes untuk per sampel.
3. Natriun karbonat bahan untuk penentuan titrasi total $\mathrm{CO}_{2}$

4. Mehtyl orange indikator untuk alkalinitas sebanyak 5 tetes.

5. $\mathrm{HCl}$ bahan untuk penentuan titrasi total alkalinitas.

Tabel 2. Parameter yang dianalisis dan pereaksi yang digunakan

\begin{tabular}{|c|c|c|c|c|}
\hline NO & Perameter yang diukur & Pereaksi digunakan & $\begin{array}{c}\text { Jumlah } \\
\text { (tetes/sampel) }\end{array}$ & Alat \\
\hline 1 & $\mathrm{~N}-\mathrm{NH}_{4}$ & Nessler & 4 tetes & Spektrofotometer, $\lambda 425 \mathrm{~nm}$ \\
\hline \multirow[t]{2}{*}{2} & $\mathrm{P}-\mathrm{PO}_{4}$ & Ammonium molibdat & 4 tetes & Spektrofotometer, $\lambda 690 \mathrm{~nm}$ \\
\hline & & $\mathrm{SnCl}_{2}$ & 2 tetes & \\
\hline \multirow[t]{3}{*}{3} & $\mathrm{~N}-\mathrm{NO}_{2}$ & Sulfanilic Acid & 4 tetes & Spektrofotometer, $\lambda 525 \mathrm{~nm}$ \\
\hline & & Alfa-Naftilamine & 4 tetes & \\
\hline & & Na-Acetat & 4 tetes & \\
\hline \multirow[t]{3}{*}{4} & $\mathrm{~N}-\mathrm{NO}_{3}$ & $\mathrm{KOH}$ & 4 tetes & Spektrofotometer, $\lambda 425 \mathrm{~nm}$ \\
\hline & & Garam signette & 4 tetes & \\
\hline & & Nessler & 4 tetes & \\
\hline 5 & $\mathrm{pH}$ & $\mathrm{PH}$ indokator & 5 tetes & \\
\hline 6 & Oksigen & Instrumen & & DO Meter YSI 30 \\
\hline \multirow[t]{2}{*}{7} & Alkalinitas & Metyl Orange & 5 tetes & \\
\hline & & $\mathrm{HCL}$ & titrasi & \\
\hline \multirow[t]{2}{*}{8} & $\mathrm{CO}_{2}$ & Phenophatalain & $2 \mathrm{ml}$ & \\
\hline & & Natrium carbonat & titrasi & \\
\hline
\end{tabular}

\section{Bahan di Laboratorium}

Bahan-bahan yang diperlukan untuk kegiatan analisis di laboratorium, secara rinci disajikan pada Tabel 2.

\section{Langkah Kerja di Lapangan}

1. Lokasi pengambilan contoh air sebanyak 11 stasiun yang telah ditentukan sebelumnya (Gambar 2), dan setiap stasiun dengan beberapa kedalaman $0 \mathrm{~m}, 2 \mathrm{~m}, 4 \mathrm{~m}, 8 \mathrm{~m}$, dan dasar perairan.

2. Mengukur $\mathrm{pH}$, oksigen terlarut, total alkalinitas, karbon dioksida bebas.

3. Mengukur kecerahan.

4. Mengukur suhu udara dan air.

5. Untuk beberapa parameter $\left(\mathrm{N}-\mathrm{NO}_{3}, \mathrm{~N}-\mathrm{NO}_{2}, \mathrm{~N}-\mathrm{NH}_{4}\right.$, $\mathrm{N}-\mathrm{NH}_{3}, \mathrm{PO}_{4}, \mathrm{SO}_{4}, \mathrm{BOT}, \mathrm{H}_{2} \mathrm{~S}$ ) yang dianalisa di laboratorium, di ambil contoh air pada kedalaman $0 \mathrm{~m}, 2 \mathrm{~m}, 4 \mathrm{~m}, 8 \mathrm{~m}$, dan dasar perairan kemudian contoh air tersebut dituang ke dalam wadah contoh air volume $500 \mathrm{cc}$ yang diberi label.
6. Mengambil contoh air pada setiap stasiun dengan kedalaman $0 \mathrm{~m}, 2 \mathrm{~m}, 4 \mathrm{~m}, 8 \mathrm{~m}$, untuk menganalisa jenis dan kelimpahan plankton, dengan penggunakan net plakton ukuran 60 micron dituangkan ke dalam wadah plastik volume $25 \mathrm{cc}$ ditambah lugol sebanyak 4 tetes dan diberi label.

7. Mencatat hasil pengukuran di lapangan pada formulir yang sudah disediakan (Lampiran 1).

\section{Langkah Kerja di Laboratorium}

1. Contoh air yang sudah diambil dari lapangan di saring Whatman ukuran $42 \mathrm{~mm}$.

2. Ambil contoh air sebanyak $10 \mathrm{ml}$ menggunakan gelas ukur.

3. Masukkan contoh air tersebut ke dalam tabung reaksi.

4. Masukkan contoh air tersebut ke dalam tabung reaksi. Untuk analisa parameter $\left(\mathrm{N}-\mathrm{NH}_{4}, \mathrm{~N}-\mathrm{NO}_{2}\right.$, $\left.\mathrm{N}-\mathrm{NH}_{3}, \mathrm{~N}-\mathrm{NO}_{3}, \mathrm{P}-\mathrm{PO}_{4}, \mathrm{SO}_{4}, \mathrm{BTO}, \mathrm{H}_{2} \mathrm{~S}\right)$ contoh air yang sudah dimasukkan ke dalam tabung reaksi ditambah pereaksi yang sesuai. 
5. Tunggu 10 menit.

6. Kemudian contoh air masukkan ke dalam cuvet. Selanjutnya untuk mengetahui data akhir besarnya konsentrasi dibaca dengan menggunakan Themo Spectronic.

7. Mencatat hasil analisa di laboratorium pada formulir yang sudah di sediakan (Lampiran 2).

\section{HASIL DAN BAHASAN}

Data kualitas air Waduk Ir. H. Djuanda bulan Januari sampai dengan Desember 2004 (Lampiran 1) dan disajikan pula dalam bentuk grafik di bawah ini.

$\mathrm{pH}$

Berdasarkan Grafik 1. menunjukkan bahwa pH berkisar 7-8,17. pH tertinggi pada bulan September dan terendah pada bulan Pebruari.

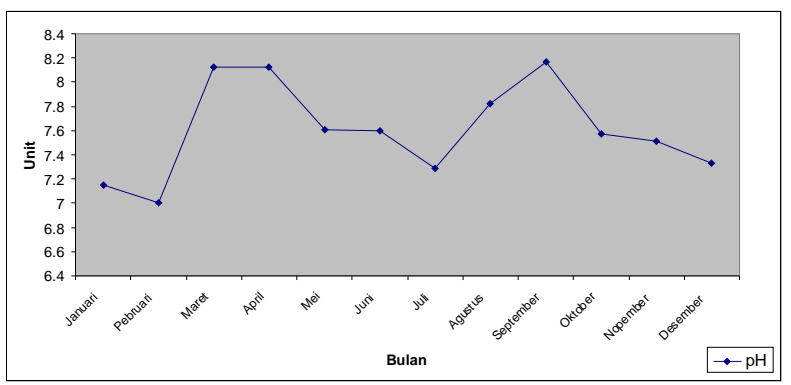

Grafik 1. pH air Waduk Ir. H. Djuanda pada tahun 2004.

Alkalinitas

Berdasarkan Grafik 2 menunjukkan bahwa Alkalinitas berkisar antara 39,71-89,48 mg/l. Alkalinitas tertinggi pada bulan Oktober dan terendah pada bulan Januari.

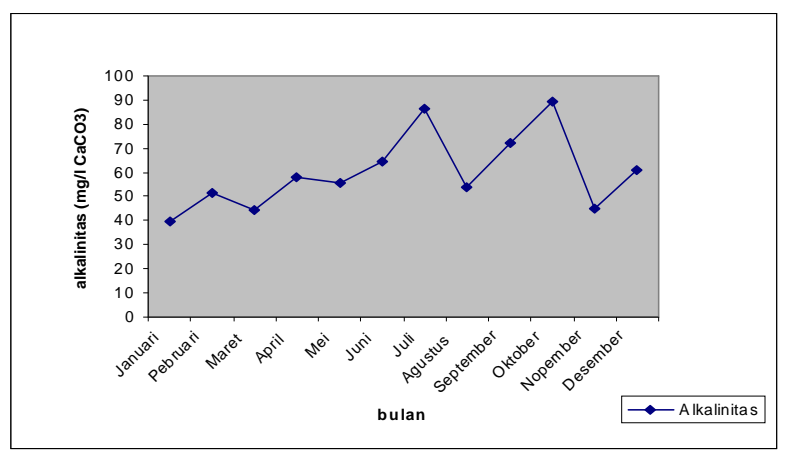

Grafik2 Alkalinitas Waduk Ir.H.Djuanda pada tahun 2004.
$\mathrm{CO}_{2}$

Berdasarkan Grafik 3 menunjukkan bahwa $\mathrm{CO}_{2}$ berkisar antara 1,04-7,68 mg/l. $\mathrm{CO}_{2}$ tertinggi pada bulan Juli dan terendah pada bulan Nopember.

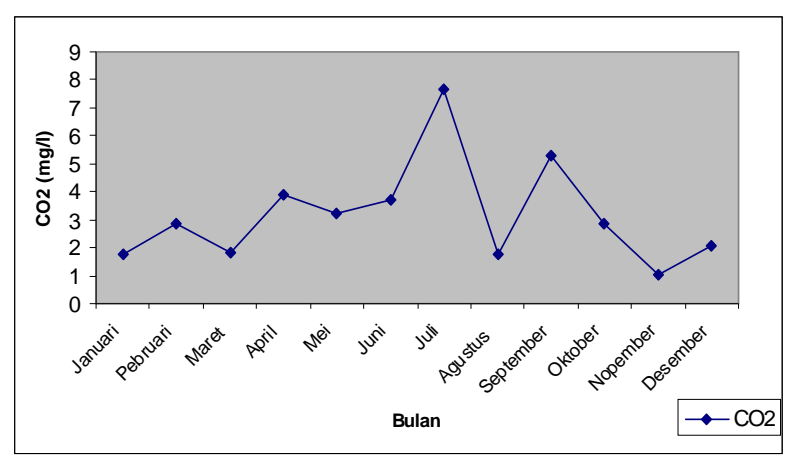

Grafik $3 \quad \mathrm{CO}_{2}$ Waduk Ir.H. Djuanda pada tahun 2004.

\section{Oksigen}

Berdasarkan Grafik 4 menunjukkan bahwa kadar oksigen di perairan waduk berkisar 3,65-9,99 mg/l. Oksigen tertinggi pada bulan Maret dan terrendah pada bulan April.

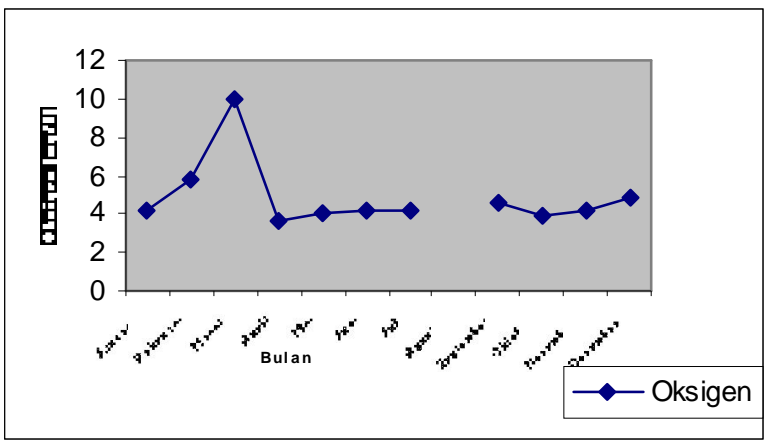

Grafik $4 \quad$ Oksigen Waduk Ir.H.Djuanda pada tahun 2004.

Amonium

Berdasarkan Grafik 5 menunjukkan bahwa Amonium di perairan waduk berkisar antara 0,016$0,305 \mathrm{mg} / \mathrm{l}$. Amonium tertinggi pada bulan Juni dan terrendah pada bulan Maret. 


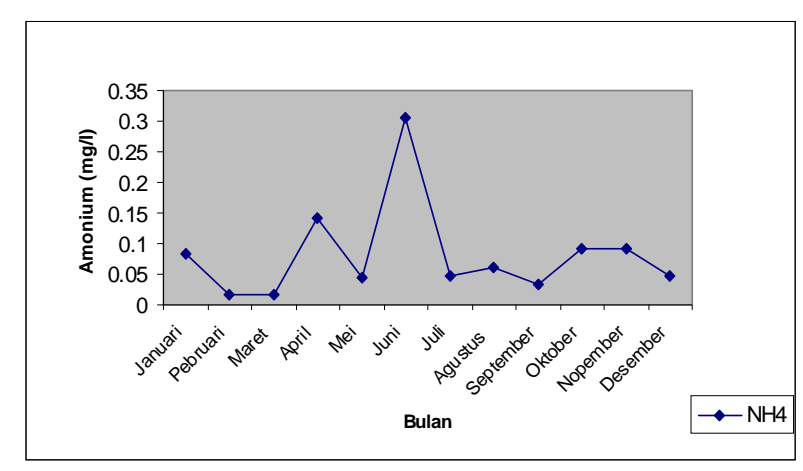

Grafik 5 Amonium Waduk Ir.H.Djuanda pada tahun 2004.

Nitrat

Berdasarkan Grafik 6 menunjukkan bahwa Nitrat di perairan berkisar antara 0,026-0,538 $\mathrm{mg} / \mathrm{l}$. Nitrat tertinggi pada bulan Mei dan terrendah pada bulan Juni.

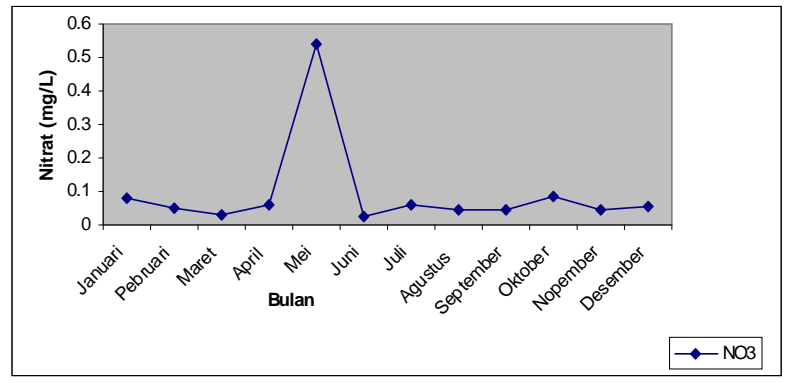

Grafik $6 \quad$ Nitrat Waduk Ir. H. Djuanda pada tahun 2004.

Nitrit

Berdasarkan Grafik 7 menunjukkan bahwa kadar nitrit di perairan waduk berkisar antara 0,001-0,493 $\mathrm{mg} / \mathrm{l}$. Nitrit tertinggi pada bulan Mei dan terendah pada bulan Maret.

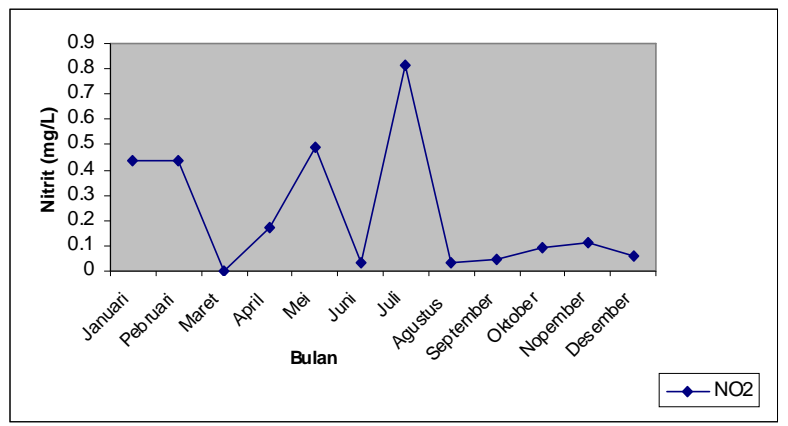

Grafik 7 Nitrit Waduk Ir.H.Djuanda pada tahun 2004.

\section{Ortho fohsfat}

Berdasarkan Grafik 8 menunjukkan kadar ortho phosphat di perairan waduk berkisar antara 0,002 $0,029 \mathrm{mg} / \mathrm{l}$. Phosphat tertinggi pada bulan Juni dan terendah pada bulan Agustus.

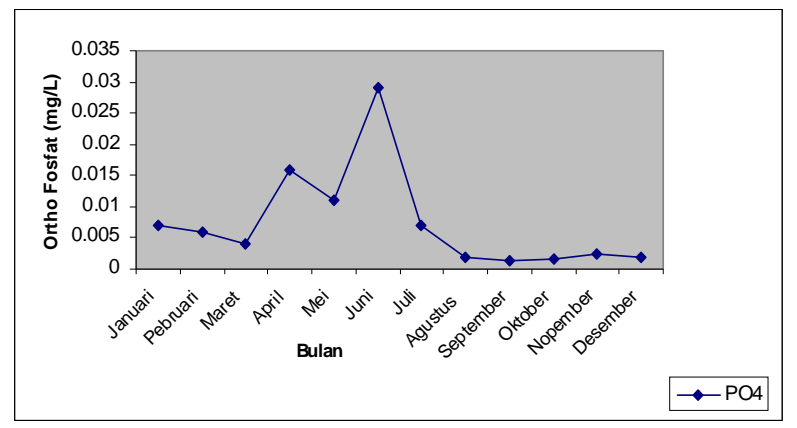

Grafik 8 Ortho phosphat Waduk Ir. H. Djuanda pada tahun 2004.

\section{KESIMPULAN}

Analisa kualitas air menggunakan metode, alat, dan pereaksi yang sudah dipersiapkan dengan teliti akan mendapatkan data yang akurat dalam waktu yang singkat.

Dari data tersebut di peroleh beberapa informasi:

1. Konsentrasi oksigen terlarut pada umumnya baik kecuali di daerah Bojong konsentrasinya lebih rendah dari kriteria yang telah di tentukan.

2. Konsentrasi oksigen terlarut di daerah Parung Kalong dan Sodong $<3 \mathrm{mg} / \mathrm{l}$.

3. Konsetrasi $\mathrm{CO}_{2}$ bebas $1,04 \mathrm{mg} / \mathrm{l}-5,32 \mathrm{mg} / \mathrm{l}$ dan $\mathrm{N}$ $\mathrm{NO}_{2} 0,001 \mathrm{mg} / \mathrm{l}-0,814 \mathrm{mg} / \mathrm{l}$ pada umumnya baik di semua stasiun.

4. Amonuim $\left(\mathrm{N}-\mathrm{NH}_{4}\right)$ yang dalam kondisi anaerob dapat berubah menjadi amoniak dan sulfat $\left(\mathrm{SO}_{4}\right)$, dan bias juga berubah menjadi sulfida $\left(\mathrm{H}_{2} \mathrm{~S}\right)$ yang bersifat racun bagi ikan.

\section{DAFTAR PUSTAKA}

Sarnita, AS. 1981. Pengelolaan perikanan Waduk Jatiluhur. Prosiding Seminar Perikanan Perairan Umum. Puslitbang Perikanan Jkt p 211-222.

Nielsen L.A. \& D.L. Jonhnson,1985. Fisheries Technigues. American fisheries Society, Bethesda Maryland. 
Lampiran I. Blangko pengamatan parameter limnologis di lapangan

Tanggal :

Stasiun :

Daerah :

Jam :
Cuaca

Kecerahan $(\mathrm{cm})$

Intensitas cahaya (Lux meter)

Warna air

Suhu Udara $\left({ }^{\circ} \mathrm{C}\right)$

\begin{tabular}{lllllll}
\hline \multirow{2}{*}{ Parameter/Sampel } & \multicolumn{5}{c}{ Kedalaman } & \multirow{2}{*}{ Keterangan } \\
\cline { 2 - 5 } & 0 & 2 & 4 & 8 & Dasar & \\
\hline Suhu air & & & & & \\
DO & & & & & \\
CO & & & & & \\
pH & & & & & \\
BOD & & & & & \\
Alkalinitas & & & & \\
Sampel air & & & & \\
Sampel Chl-a & & & & \\
Keterangan tambahan & & & & \\
\hline
\end{tabular}




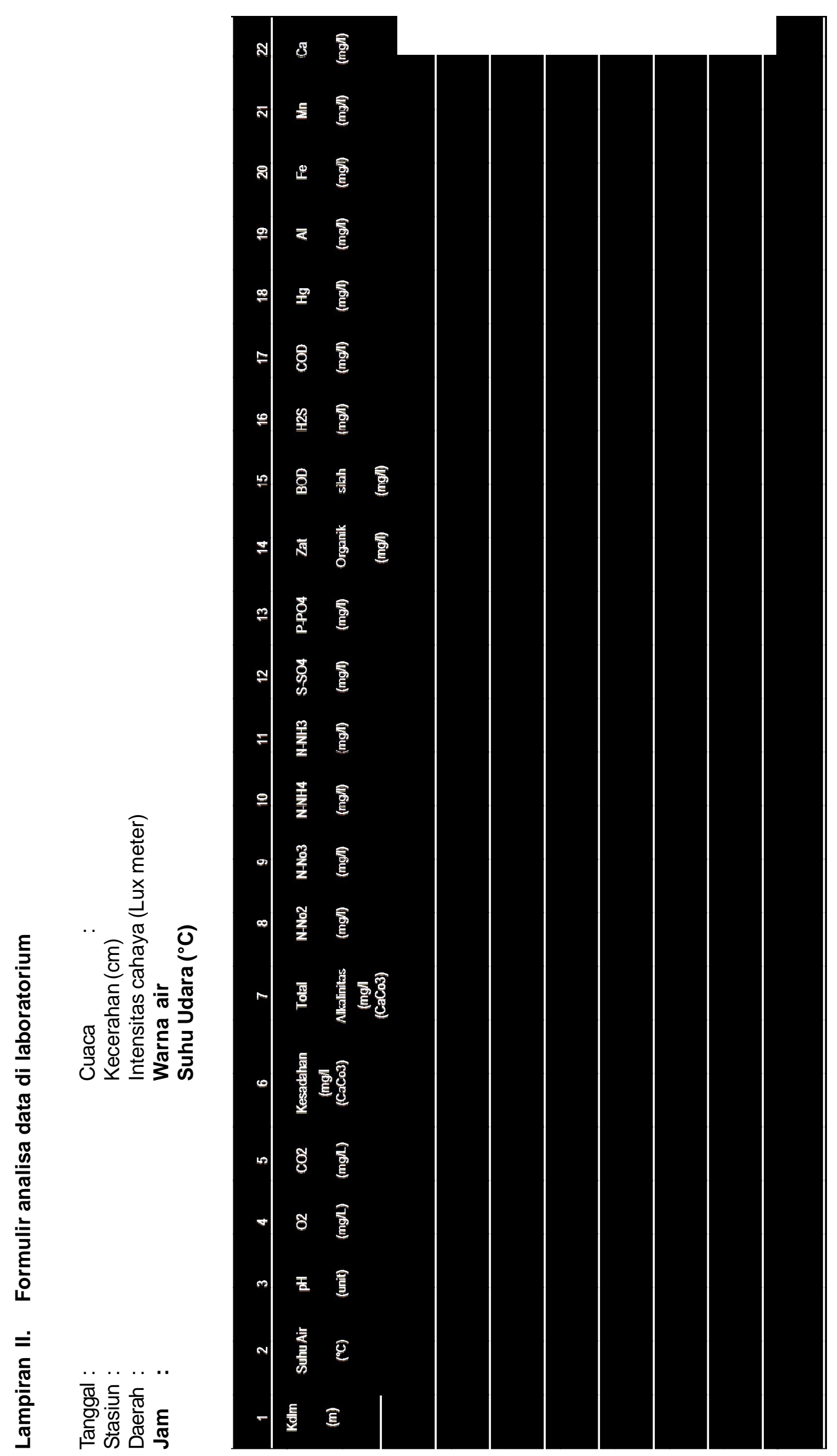

